Journal of Engineering and Applied Sciences 14 (22): 8196-8207, 2019

ISSN: 1816-949X

(C) Medwell Journals, 2019

\title{
Fatigue Assessment of ALSABTEA Bridge under Dynamic Loads
}

\author{
Qassim Yahyea Hamood and Ali Laftah Abaas \\ Department of Civil Engineering, University of Diyala, Diyala, Iraq
}

\begin{abstract}
Fatigue of the structural elements that fail due to the cumulative damaged by the connected between the microscopic interior cracks represents the main problem of structure such as bridges. The source of fatigue in bridges is amplitude dynamic loading from vehicles during the service life of the bridge that cause fatigue. Composite bridge is the one of different types of bridges that may contain steel girder connected with deck concrete slab by means of shear connectors to transferee the trucks and other loadings to the steel girders. Due to varied amplitude of velocity ranges during the life of the bridge that caused damaged structure on the bridge such as increased in deflections and stresses. In present study, ALSABTEA composite bridge in Diyala, Iraq that designed and constructed to work as full interaction is analyzed under the effects of repeated loading based on loadings codes specifications such as AASHTO using finite elements approach by ANSYS packages. The parameters taking into account are truck loading and velocity speed as low, medium and high. The analysis results indicated that the damage index D for load cases not reach to unity but the maximum value is $<0.2 \%$ in case of HS20 loading.
\end{abstract}

Key words: Composite bridge, shear connectors, repeated loading, finite elements, ANSYS, damage

\section{INTRODUCTION}

The repeated load that applied on the bridge developed micro cracks and lead to serious fatigue failures. Leitao et al. (2011), studied the fatigue life of composite bridge due to the effects of vehicles loadings. Numerical analysis by finite elements approach was used to evaluate the composite bridge by applied stress with number of cycles. The analysis results indicated that the structural system service life values as compared with standards codes uch as AASHTO and Euro Code 3 show higher than those proposed by the design codes. Zhang (2012), studied and examined existing bridge under the effect of dynamic loading due to repeated vehicles. Stresses and number of cycles with short and long span bridge were check out and concluded that the vehicle speed affects the fatigue reliability and fatigue life of the bridges. Salem (2013), assessment of bridge subjected to dynamic and fatigue loadings due to traffic effects. According to, the numerical analysis concluded that the traffic rates affect the dynamic performances of bridges life. Lin et al. (2013), investigated the composite beams under the effects of repeated loading. Based on the test results, the load caused initial cracks that the fatigue had only little influence on the beam stiffness. ACI (2014), investigated the behavior of the composite beams that subjected to repeated loadings. Series of push-out tests were adopted based on the Euro Code 4 and full scale composite beams subjected to high cyclic loadings. Test results were analyzed and used to suggest a new design method to predict the remaining strength life of the headed shear studs after high cycle loading was applied. Wang et al. (2016), determined the required numbers of cycles for fatigue design for the composite bridge due to the vehicles loadings. Different parameters such as vehicles loading, surface condition of the deck and the bridge span were considered in the study. Results analysis indicated that the surface conditions of the road more effects on the numbers of cycles. Saddiq and Hassan (2016), studied the transient stress and their effects on the simply supported beams due to moving loadings. Euler-Bernoulli theory and fourier series were adopted in the analysis using finite elements approach by ANSYS by taking into account parameters such as speed and loads in magnitudes and locations. Based on the analysis results, they concluded that the speed more effects than the loads on the behavior of beams.

In present study, the performance fatigue of existing ALSABTEA bridge under repeated loading by considering parameters such as vehicles speed and loadings based on AASHTO specifications using a finite elements approach to simulate the composite girder.

\section{MATERIALS AND METHODS}

The mechanical properties of all components such as deck concrete slab, steel girder, shear connecters and

Corresponding Author: Qassim Yahyea Hamood, Department of Civil Engineering, University of Diyala, Diyala, Iraq 


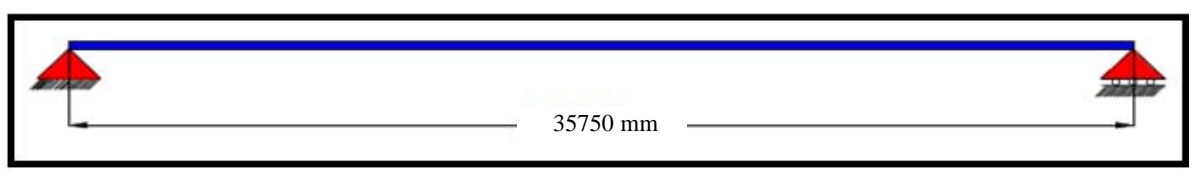

Fig. 1: Simply supported bridge span

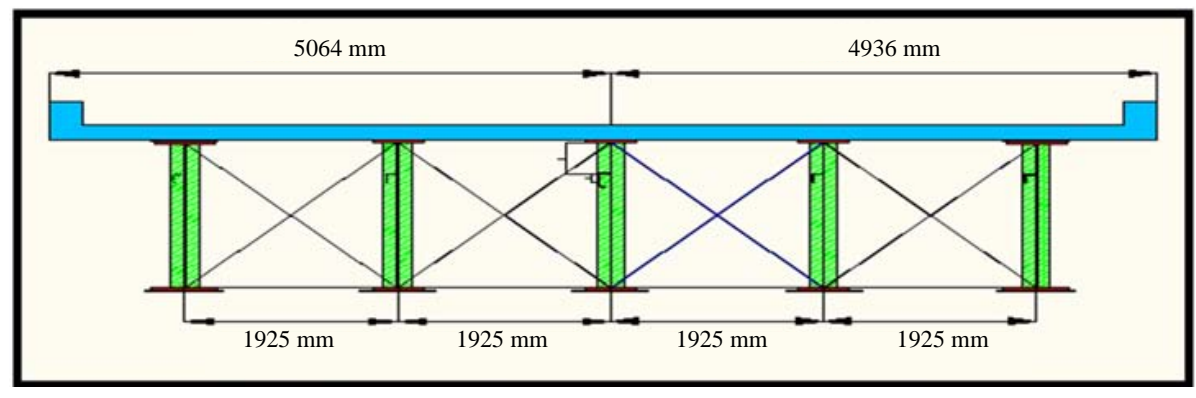

Fig. 2: Bridge components

\begin{tabular}{|c|c|c|}
\hline \multicolumn{2}{|c|}{ Material types/Parameters Definitions } & \multirow{2}{*}{ Values } \\
\hline & & \\
\hline $\mathrm{fc}^{\prime}$ & Ultimate compressive strength ( $\mathrm{MPa})$ & 28 \\
\hline $\mathrm{E}_{\mathrm{c}}$ & Young's modulus of elasticity (MPa) & 25000 \\
\hline $\mathrm{v}_{\mathrm{s}}$ & Poisson's ratio & 0.15 \\
\hline \multicolumn{3}{|c|}{ Steel girder } \\
\hline \multirow[t]{2}{*}{$f_{y}$} & Yield strength (MPa)-web & 319 \\
\hline & Yield strength (MPa)-flange & 385 \\
\hline $\mathrm{E}_{\mathrm{S}}$ & Modulus of elasticity (MPa) & 200000 \\
\hline $\mathrm{v}_{\mathrm{s}}$ & Poisson's ratio & 0.2 \\
\hline \multicolumn{3}{|c|}{ Reinforcement } \\
\hline $\mathrm{E}_{\mathrm{S}}$ & Modulus of elasticity (MPa) & 200000 \\
\hline$f_{y}$ & Yield strength (MPa) & 420 \\
\hline$v_{s}$ & Poisson's ratio & 0.3 \\
\hline \multicolumn{3}{|c|}{ Steel plate } \\
\hline$f_{y}$ & Yield strength (MPa) & 319 \\
\hline $\mathrm{E}_{\mathrm{S}}$ & Modulus of elasticity (MPa) & 200000 \\
\hline$v_{s}$ & Poisson's ratio & 0.3 \\
\hline \multicolumn{3}{|c|}{ Shear connector } \\
\hline$f_{y}$ & Yield strength (MPa) & 319 \\
\hline $\mathrm{E}_{\mathrm{S}}$ & Modulus of elasticity (MPa) & 200000 \\
\hline & Poisson's ratio & 0.3 \\
\hline
\end{tabular}

steel reinforcements as actual from the design criteria of the bridge. The compressive strength and modulus of elasticity for ordinary concrete is lists in Table 1 and 2. Mass of concrete and reinforcement needed in dynamic analysis that considered based on the geometry dimensions of concrete slab and diameter of reinforcement with density $25-78.5 \mathrm{kN} / \mathrm{m}^{3}$, respectively.

Bridge descriptions: The bridge consisted of multi steel girders has uniform in geometry and arranged at uniform spacing across the width of the bridge with three lanes road with a rigid traffic barrier as shown in Fig. 1. The length of the part that has been rehabilitated $36 \mathrm{~m}$ and width $21 \mathrm{~m}$. In present study the interior composite concrete steel girder is select because it represent the worst case. The center to center span of the composite bridge is $(35.75 \mathrm{~m})$ with $(200 \mathrm{~mm})$ deck slab thickness and reinforced by steel reinforcement with diameter of $16 \mathrm{~mm}$ at $200 \mathrm{~mm}$ center to center for bottom reinforcement and at the top reinforcement with diameter of 13-200 mm center to center designed based on the AASHTO ASD (Anonymous, 2018) with top and bottom cover ( 35 and 25 $\mathrm{mm}$ ), respectively. The bridge span with boundary conditions at the ends as shown in Fig. 1 and the bridge structural components as deck slab, steel girders and crossing bars shown in Fig. 2.

The steel girder with dimensions as shown in Fig. 3 was constructed by hot steel and the stiffeners are distributed along the span each $1711 \mathrm{~mm}$ with crossing bars at each $7090 \mathrm{~mm}$ center to center. The framing plan of interior steel girder shown in Fig. 3 and the shear connector as channel with dimensions as shown in Fig. 4.

Finite element simulation: The Finite Element Analysis (FEA) used to simulate the composite bridge taking into accounts all actual dimensions and mechanical properties of each materials by selects the structural composed of elements connected together at a finite number of nodes that represents in performance the real behavior of composite girder and assume that the composite plate glider behaved as full interaction based on the designer assumptions as shown in Fig. 5. The Software ANSYS AASHTO (1996) was adopted to simulate the composite bridge that subjected to repeated dynamic loadings. The numerical method by finite elements approach used to simulate the composite bridge by selected a suitable elements type. SOLID65, this element for concrete is capable of plastic deformation, cracking in three orthogonal directions and crushing. LINK180, element is used to model steel reinforcement, this element is a 3D 
Table 2: Steel girder properties

\begin{tabular}{lcccc}
\hline No. of girders & Girder spacing $(\mathrm{mm})$ & Span length $(\mathrm{mm})$ & Web yield strength $\mathrm{f}_{\mathrm{y}}(\mathrm{MPa})$ & Flange yield strength $\mathrm{f}_{\mathrm{y}}(\mathrm{MPa})$ \\
\hline 5 & 1925 & 35750 & 319 & 385
\end{tabular}
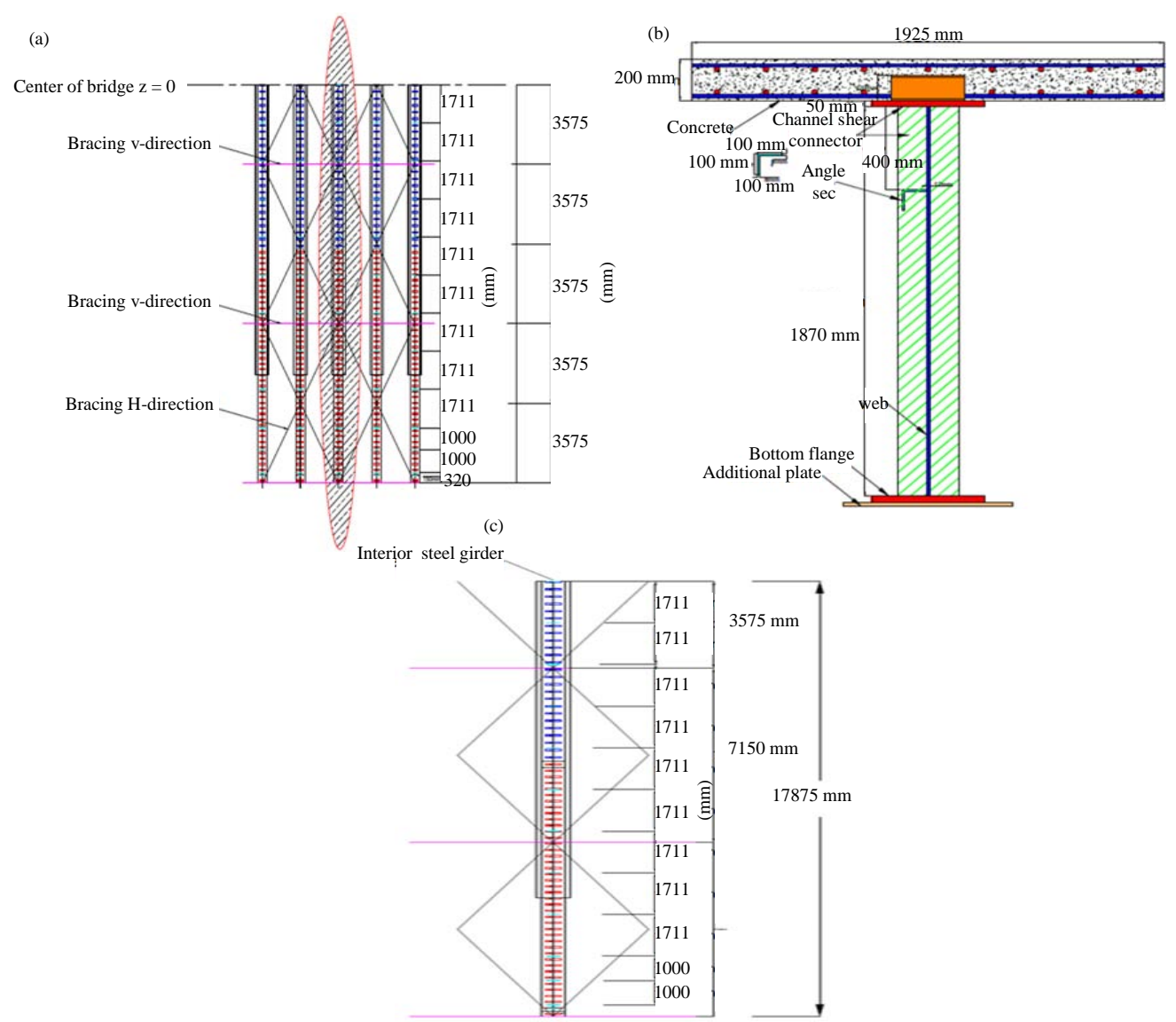

Fig. 3: a-c) Framing plan of interior steel girder
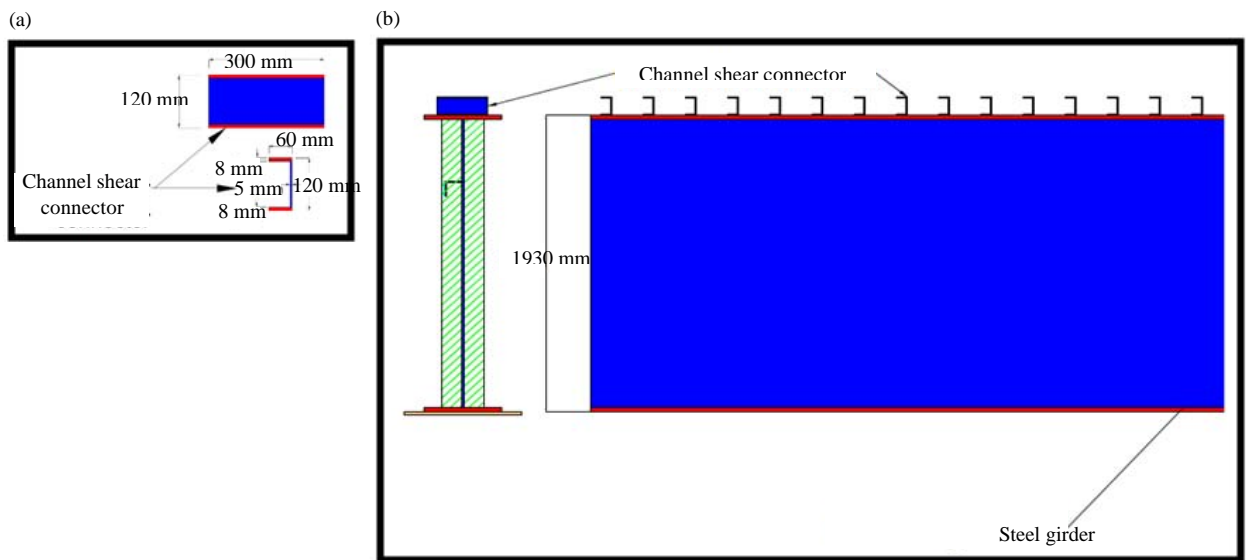

Fig. 4: a and b) Channel dimensions as shear connector

spar element and it has two nodes with $3^{\circ}$ of freedom at each node translations in the nodal $x-z$ directions.
SHELL181 element was used for modeling the steel plate, this type of element is suitable for analyzing thin to 

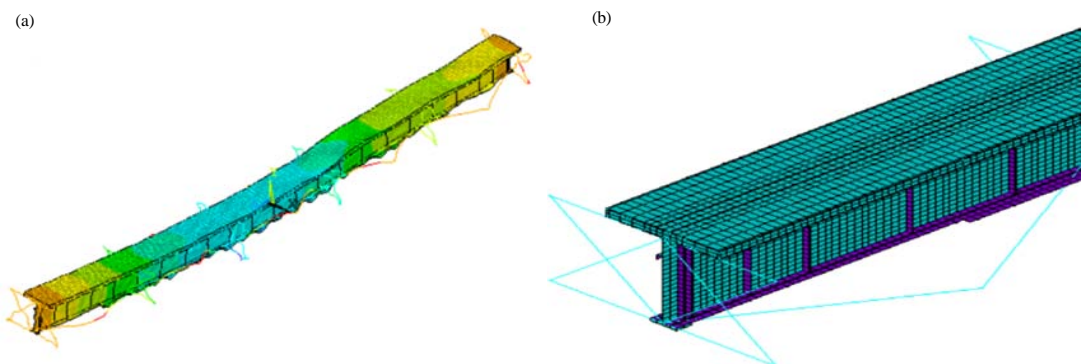

Fig. 5: $a$ and b) Model of finite element
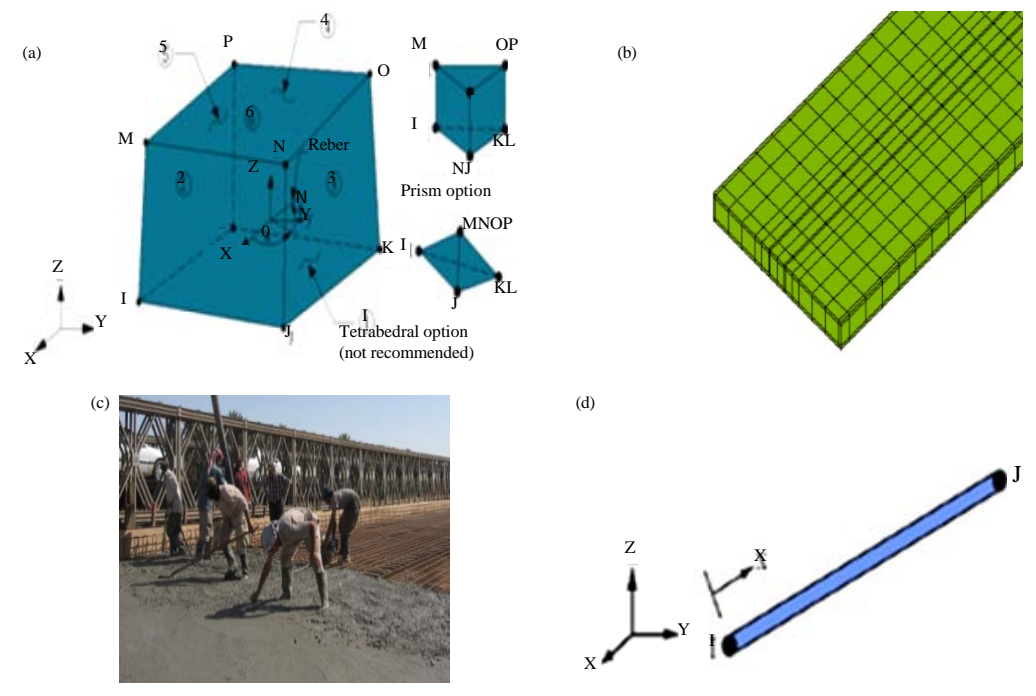

(d)

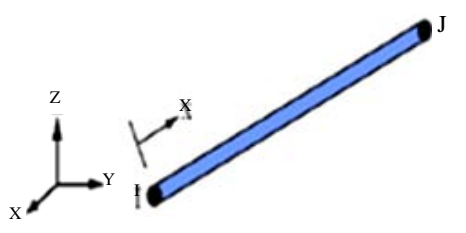

Fig. 6: a, b) SHELL181 geometry (AASHTO., 1996); c) Concrete slab in actual case and d) LINK180 geometry
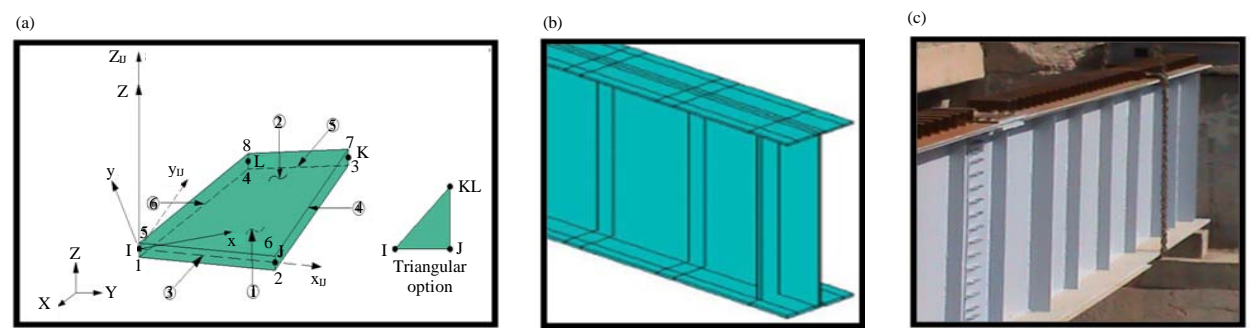

Fig. 7: a, b) SHELL181 geometry (AASHTO., 1996) and c) Steel girder in actual case

shell structures. It is a four node element with $6^{\circ}$ of freedom at each node translations in the $\mathrm{x}-\mathrm{z}$ directions and rotations about the $\mathrm{x}-\mathrm{z}$ axis. SOLID185 element is used to simulating the steel columns because of a three dimensional of solid structures that defined by eight nodes with $3^{\circ}$ of freedom at each node. Surfaces-to-surfaces contact is assumed to describe the relationship between top steel girder and the bottom of deck slab, so that, the elements that selects are
(CONTA-174 and TARGE 170), simulating the composite bridge deck's full interaction. Show the LINK180 and SOLD65 is select to geometry elements as shown in Fig. 6 (AASHTO., 1996). The steel girder representation in the finite elements is used SHELL181as shown in Fig. 7 (AASHTO., 1996). At the loading position, steel plates are added to avoid concentration to simulate the steel plate SOLID185 as shown in Fig. 8 (AASHTO., 1996). 
Elements of nonlinear springs COMBIN39 is used to model the channel shear connectors. COMBIN39 elements represents the load opposite slip connector's behavior (Abbas, 2011). The geometry, node location and the system of coordinate for these elements are shown in Fig. 9 in which the points represent the coordinate of load slip from experimental push-out test under static load (Panchal, 2014). Figure 10 the bracing between steel girders are simulated by used two node beam element BEAM1 88 with $6^{\circ}$ of freedom at each node.

The numbers of meshes are for all elements are selects to match the results accuracy and convergence requirements, so that, the convergence criteria as displacement with convergence $(5 \%)$ of tolerance. The Frontal solver numerical roots method is adopted to determine the unknown because some of results in dynamic analysis may contain complex roots.

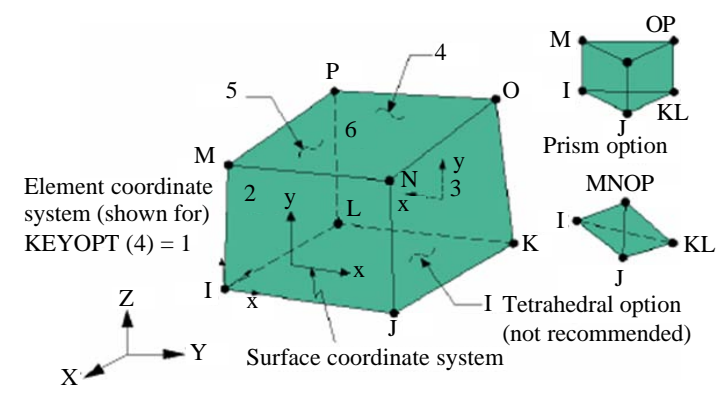

Fig. 8: SOLID185 geometry (AASHTO., 1996)

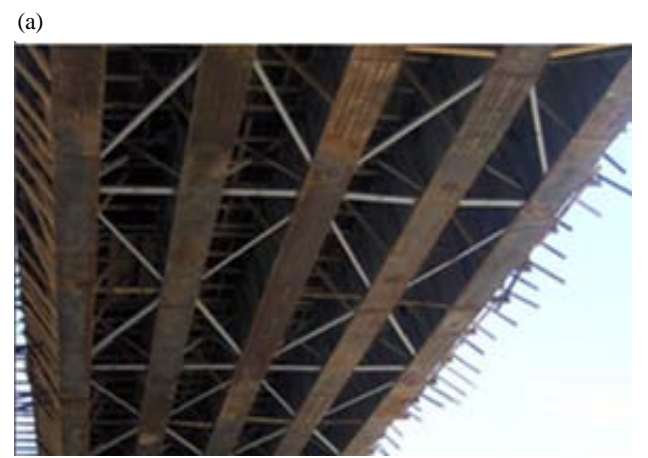

Vibration modes: Figure 11 represents the natural frequency determined from modal analysis for the composite plat girder (vibration modes) as shown in Table 3 .

Dynamic analysis: The response of composite bridge that subjected to moving loads (truck loadings) complex in behavior due to consists from different materials has

\begin{tabular}{lcc} 
Table 3: Vibration modes & \\
\hline Mode shapes & Frequencies $(\mathrm{Hz})$ & Time periodic $(\mathrm{sec})$ \\
\hline 1 & 2.560 & 0.3910 \\
2 & 3.840 & 0.2600 \\
3 & 10.136 & 0.0986 \\
4 & 11.656 & 0.0858 \\
\hline
\end{tabular}

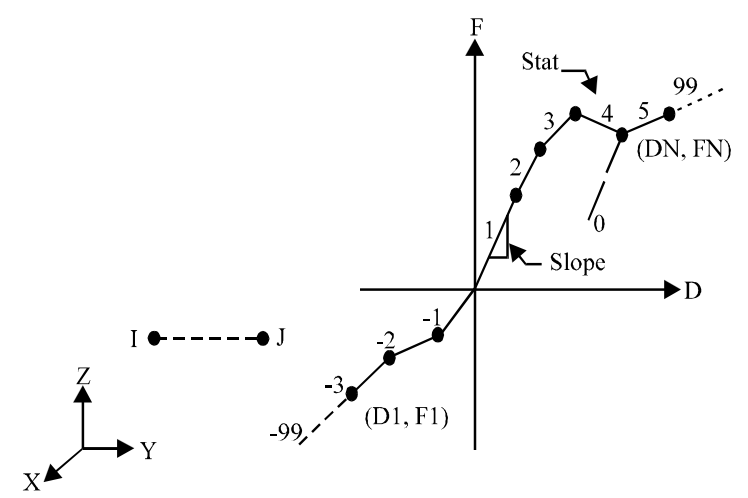

Fig. 9: COMBIN39 geometry (AASHTO., 1996)

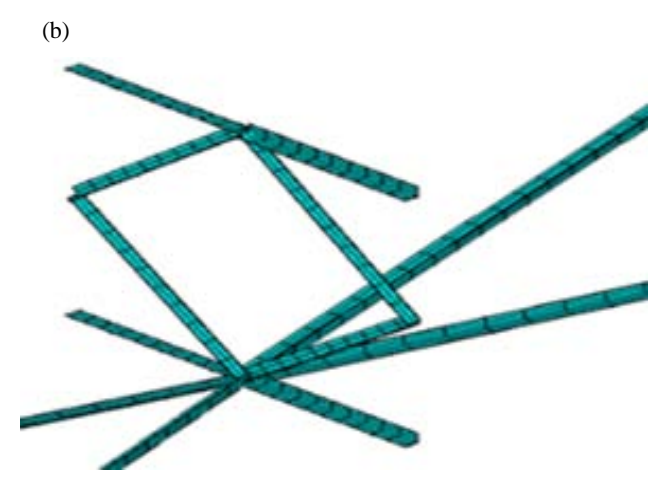

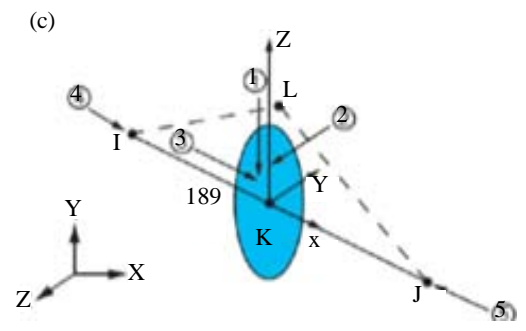

Fig. 10: a) Bracing in actual case and b, c) Beam geometry (AASHTO., 1996) 

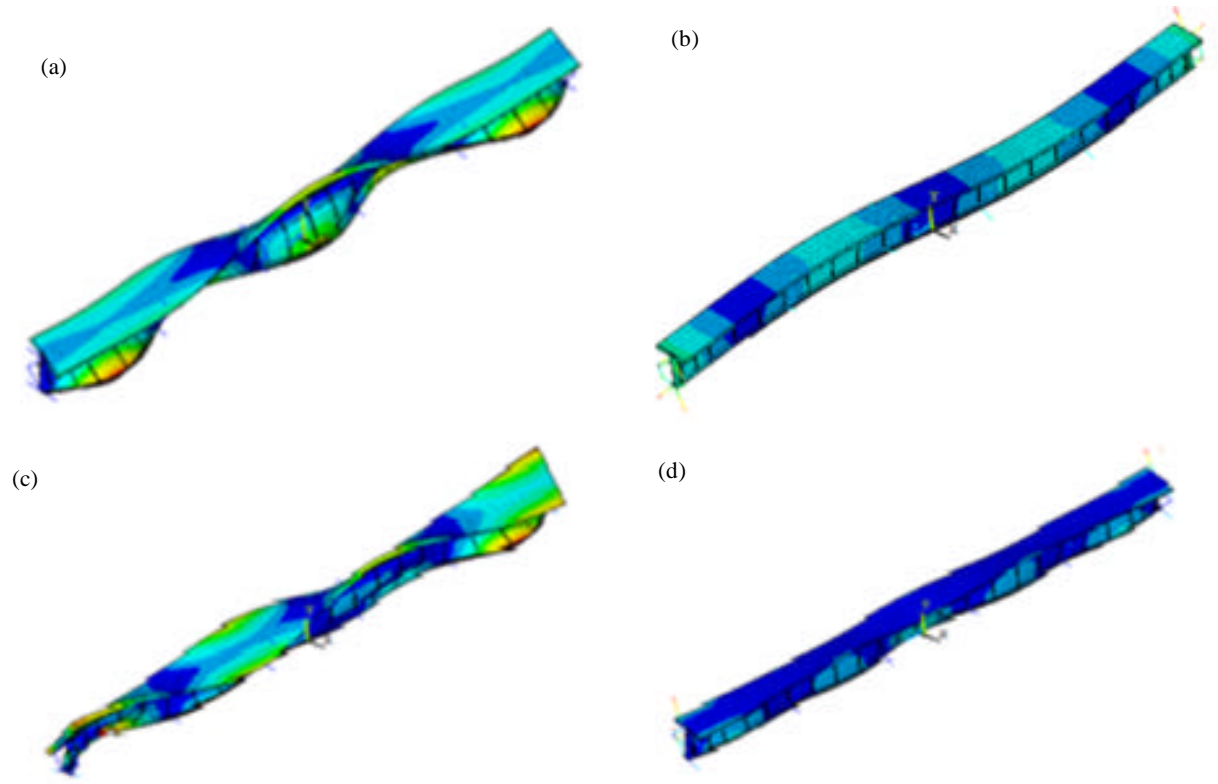

Fig. 11: Vibration modes of the bridge obtained using the finite element model: a) $\mathrm{f}_{01}=2.56 \mathrm{~Hz}$; b) $\mathrm{f}_{02}=3.84 \mathrm{~Hz}$; c) $\mathrm{f}_{03}=10.136 \mathrm{~Hz}$ and d) $\mathrm{f}_{04}=11.656 \mathrm{~Hz}$

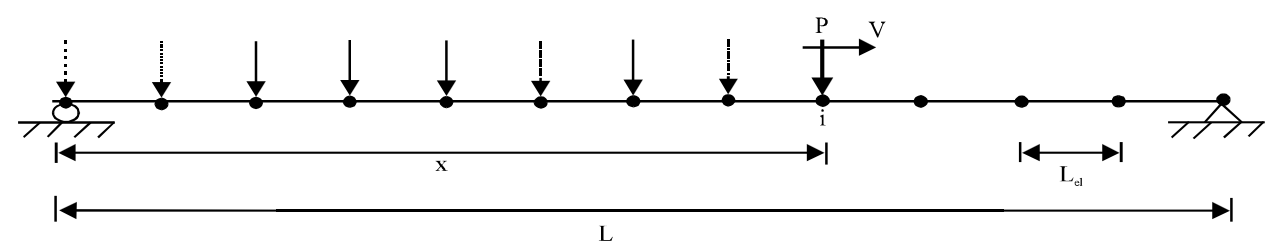

Fig. 12: Moving load modeling

different in modulus of elasticity and poisson's ratio and the difficulty to express the interaction relationships at the interface between contact loadings and the top surface of the bridge, so that, the full performance of such bridges become complicated. The bridge response against dynamic loadings affected by many parameters such as vehicle speed, vehicle cycles and the bridge components. In present study, the moving load is modeled by applying the concentrated load at nodes with the duration equal to element length divided by the selected moving load velocity as shown in Fig. 12 (Sadiq and Hassan, 2016). The assumptions for simulation and applied loading on the top face of the bridge as follows: the load-time performance as shown in Fig. 13. The loads applied exactly on nodes.

Loadings: The superimposed dead load and live load based on the AASHTO ASD (Anonymous, 2018) as truck live load as shown in Fig. 14. The live loading that applied at the top of deck slab bridge based on the AASHTO bridge specification (Anonymous, 2018) as shown in

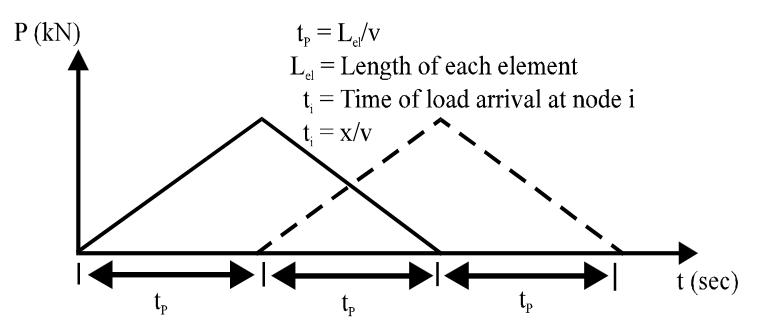

Fig. 13: Types of time function

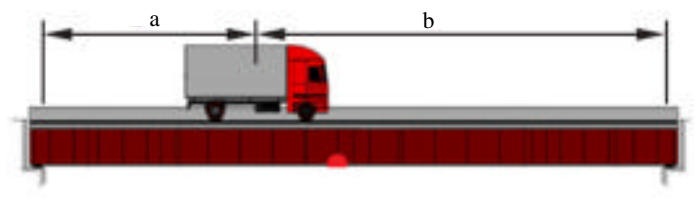

Fig. 14: Fatigue truck loading

Table 4. The bridge was analyzed as simply supported that simulated as actual because of there was an expansion joints between adjacent spans. 
Table 4: AASHTO truck loadings (AASHTO., 1996)

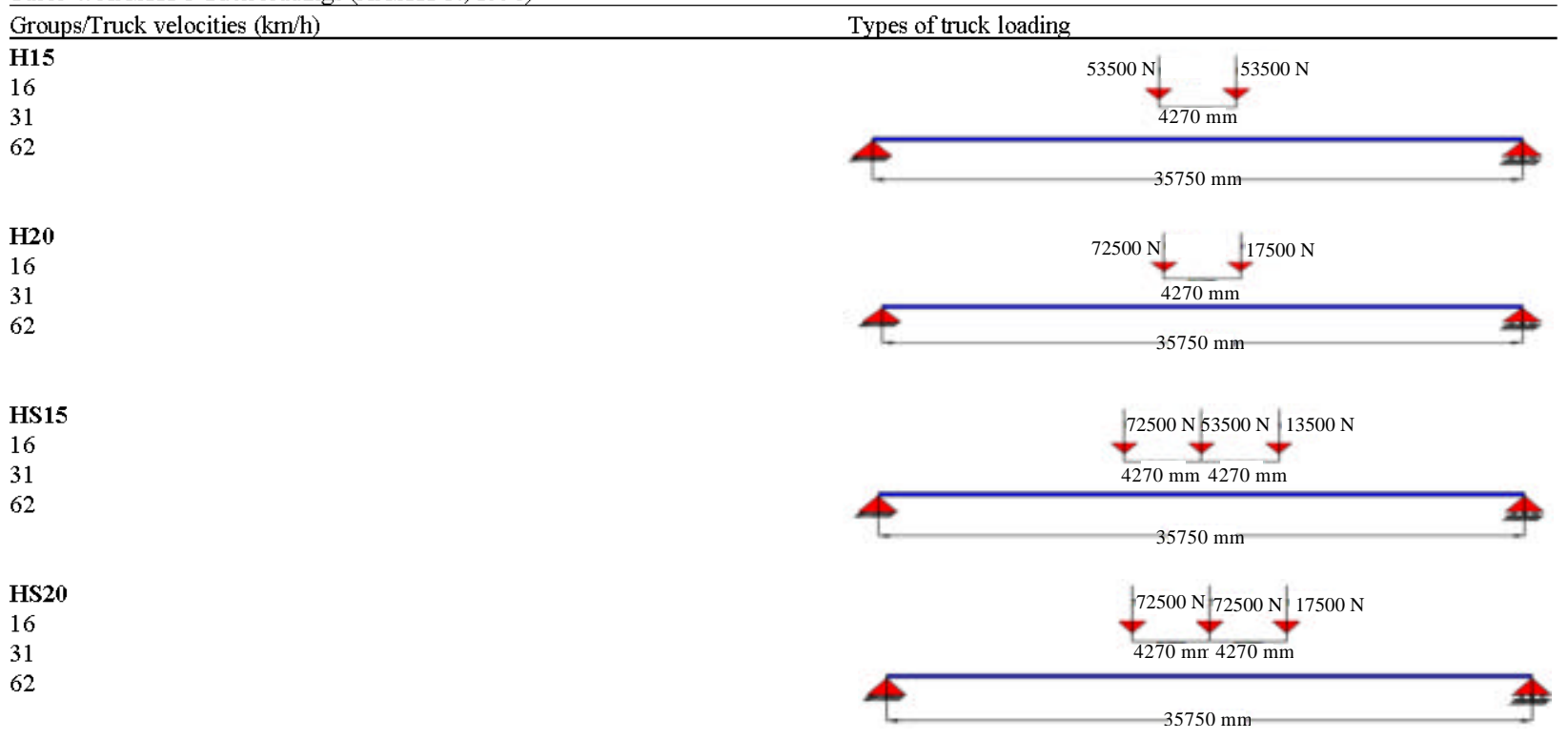

Different parameters are taken into accounts such as apply external trucks loading based on AASHTO specifications and different velocities, according to the classified speed as low, medium and high (Law and Zhu, 2004). The applied load that adopt are classify as (HS20, $\mathrm{H} 20$, HS15 and H15) with each loading there are three velocities $(16,31$ and $62 \mathrm{~km} / \mathrm{h})$. The methodology that adopted to evaluate the existing ALSABTEA bridge is apply maximum absolute moments principle that produce maximum stress on the composite bridge.

\section{RESULTS AND DISCUSSION}

Figure 15 represent the full performance of deflection with time for all loading with different velocities. The deflection increase as applied loading increase such that the deflection under the effects of (HS20, H2O, HS1 5 and $\mathrm{H} 15)$ for velocity $16 \mathrm{~km} / \mathrm{h}(43.5,28.3,37.82,21.47 \mathrm{~mm})$ and $31 \mathrm{~km} / \mathrm{h}(49.48,30.90,43.20$ and $26.93 \mathrm{~mm})$ and $62 \mathrm{~km} / \mathrm{h}$ $(57.12,36.87,50.18$ and $29.79 \mathrm{~mm})$, respectively. As the velocity increase the deflection under the effect of a specific load increase due to increase in kinetic energy. At specific value of deflection the time required increase as the velocity of truck loading decrease and become low due to the time required to pass the same distance will be more in case of increase of time.

Figure 16 show the stress variation with respect to time measured at the bottom as the velocity increase produces bending stress more than when the velocity become low. Such that the stress under the effects of (HS20, H20, HS15 and H15) for velocity $16 \mathrm{~km} / \mathrm{h}(81.9$, $56.70,71.82$ and $43.62 \mathrm{MPa})$ and $31 \mathrm{~km} / \mathrm{h}(88.13,60.59$,
76.91 and $48.53 \mathrm{MPa})$ and $62 \mathrm{~km} / \mathrm{h}(101.53,67.53,89.29$ and $54.3 \mathrm{MPa})$, respectively. At specific bending stress the time required to produce stress magnitude relay on the truck velocity in the time required become more in the velocity is low for same distance that required for traveling. The bending stress increase as the applied truck loading increase because when the applied loading increase the maximum external moment increase that lead to increase in the internal stresses of the composite bridge.

Figure 17 represent the bending stress of the interface between the steel girder and bottom of concrete slab that lie above of neutral axis, so that, the sign convention negative because of part of steel girder within compressive zone of composite action. The bending stresses at this location lower in magnitude than in the bottom of steel girder due to the low are of moment. The bending stress become less when decrease in velocity of truck because of decrease kinetic energy (that decrease in case of velocity decreased with constant weight or mass of vehicle), at specific of pure bending stress the time required to reach this specific value become more when the truck velocity is less this is because of time required at a constant interval spacing or distance depend on the magnitude of velocity, so that, the time become more when the velocity become less. Such that the stress under the effects of (HS20, H2O, HS15 and H15) for velocity $16 \mathrm{~km} / \mathrm{h}(-41.45,-26.88,-36.62$ and $-21.48 \mathrm{MPa})$ and $31 \mathrm{~km} / \mathrm{h}$ $(-45.56,-27.63,-40.29$ and $-23.14 \mathrm{MPa})$ and $62 \mathrm{~km} / \mathrm{h}(-55.68$, $-36.53,-49.36$ and $-29.16 \mathrm{MPa})$, respectively.

Figure 18 shows the shear stress distribution at the location of left support and represent the cumulative 

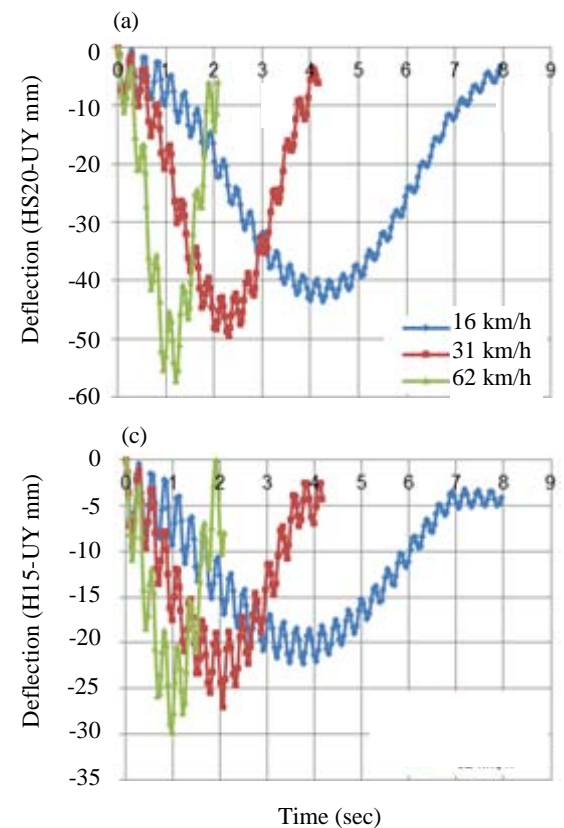
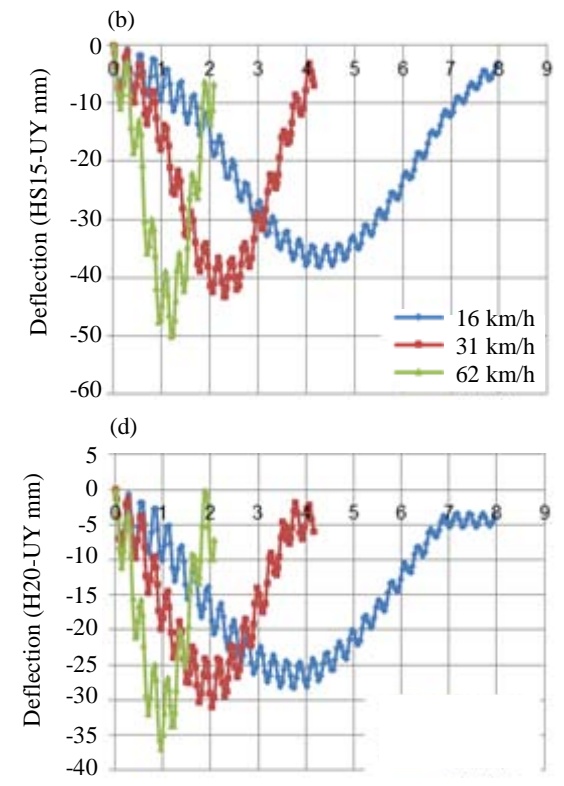

Time (sec)

Fig. 15: Deflectionat bottom of steel girder for group: a) HS20; b) HS1 5; c) H1 5 and d) H2O
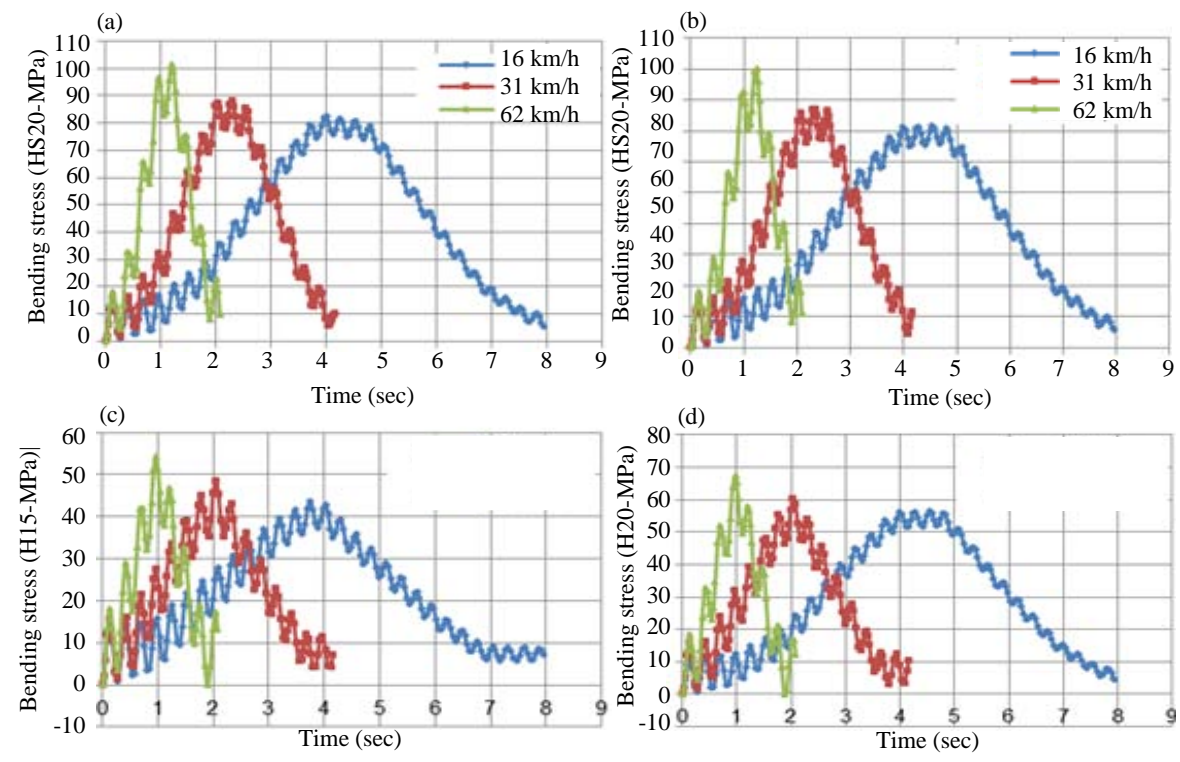

Fig. 16: Bending stressat bottom of steel girder for group: a) HS20; b) HS15; c) H15 and d) H2O

shear developed due to applied external loading through time interval. The performance of shear stress increase of low velocity becomes less of the shear force required become less. Such that the shear stress under the effects of (HS20, H20, HS15 and H15) for velocity $16 \mathrm{~km} / \mathrm{h}(-5.75$, $-3.86,-5.1$ and $-3.07 \mathrm{MPa})$ and $31 \mathrm{~km} / \mathrm{h}(-6.38,-4.14,-5.56$ and $-3.25 \mathrm{MPa})$ and $62 \mathrm{~km} / \mathrm{h}(-7.46,-5.01,-6.68$ and -4.01 $\mathrm{MPa}$ ), respectively.
Figure 19 expresses the pure bending stress of the top face of concrete slab all bending stress are less magnitude because of the lower value of distance from the top face of concrete and the centroid of cross sectional area of composite bridge due to the location of neutral axis that near the interface of steel girders and concrete slab. The magnitude and performance of bending stress with time as the same reasons mentioned above. Such that 

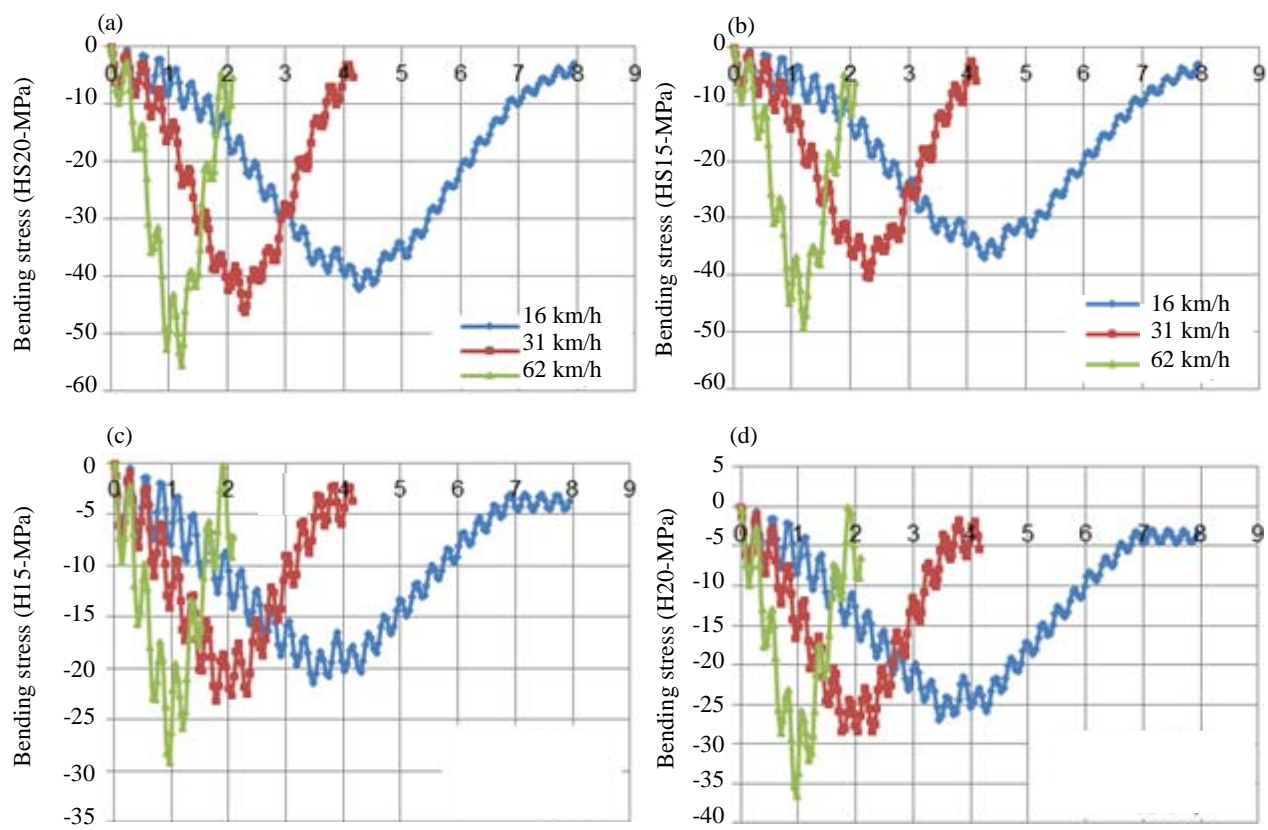

Time (sec)

Time (sec)

Fig. 17: Bending stress at interface between concrete and steel girder for group: a) HS20; b) HS15; c) H1 5 and d) H2O
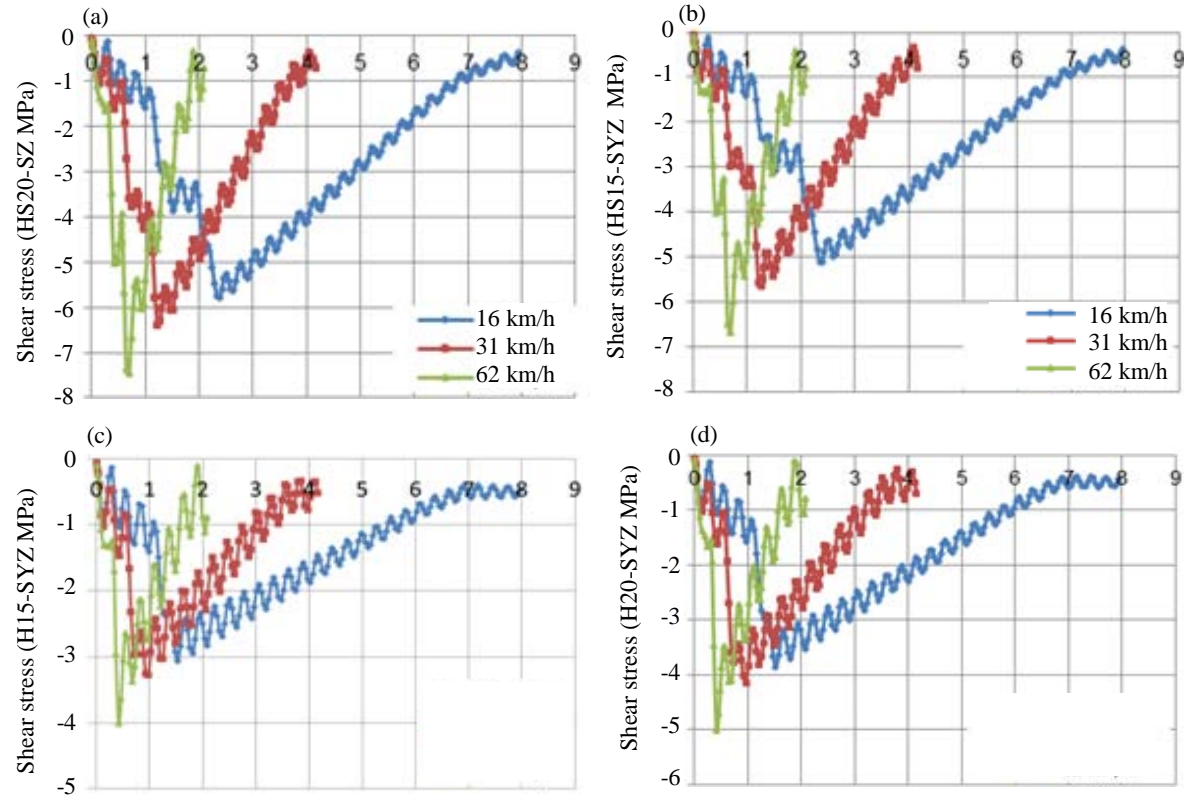

Time (sec)

Time (sec)

Fig. 18: Shear stress at interface between concrete and steel girder for group: a) HS20; b) HS1 5; c) H1 5 and d) H2O

the stress under the effects of (HS20, H20, HS15 and H15) for velocity $16 \mathrm{~km} / \mathrm{h}(-6.45,-4.26,-5.63$ and $-3.47 \mathrm{MPa})$ and $31 \mathrm{~km} / \mathrm{h}(-6.89,-4.82,-6.11$ and $-3.85 \mathrm{MPa})$ and $62 \mathrm{~km} / \mathrm{h}$ $(-8.78,-5.79,-7.89$ and $-4.68 \mathrm{MPa})$, respectively.
Fatigue analysis: Evaluation of the fatigue in the composite bridge due to repeated loadings by measure the cumulative damaged based on the Euro Code 3 was adopted for assessments. In present study, the fillet weld 

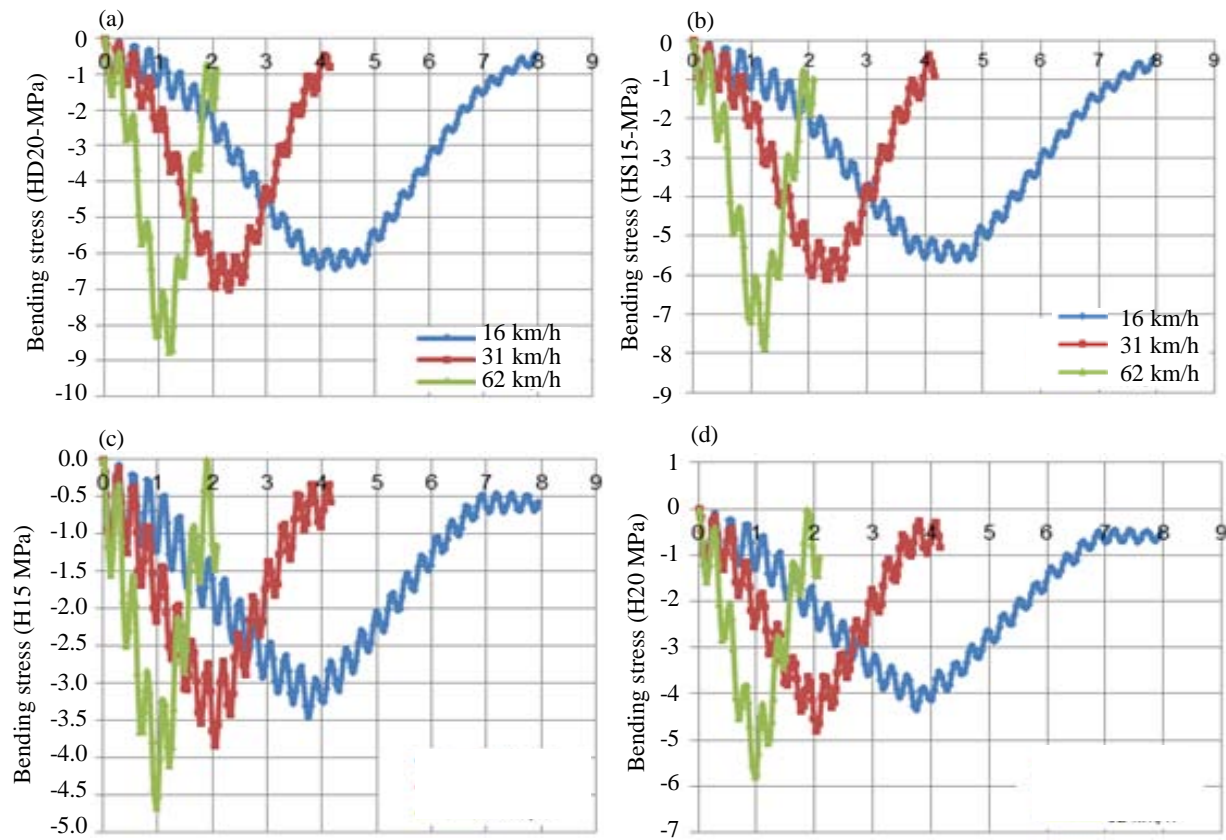

Time (sec)

Time (sec)

Fig. 19: Bending stressat top face of concrete slab deck for group: a) HS20; b) HS1 5; c) H15 and d) H2O
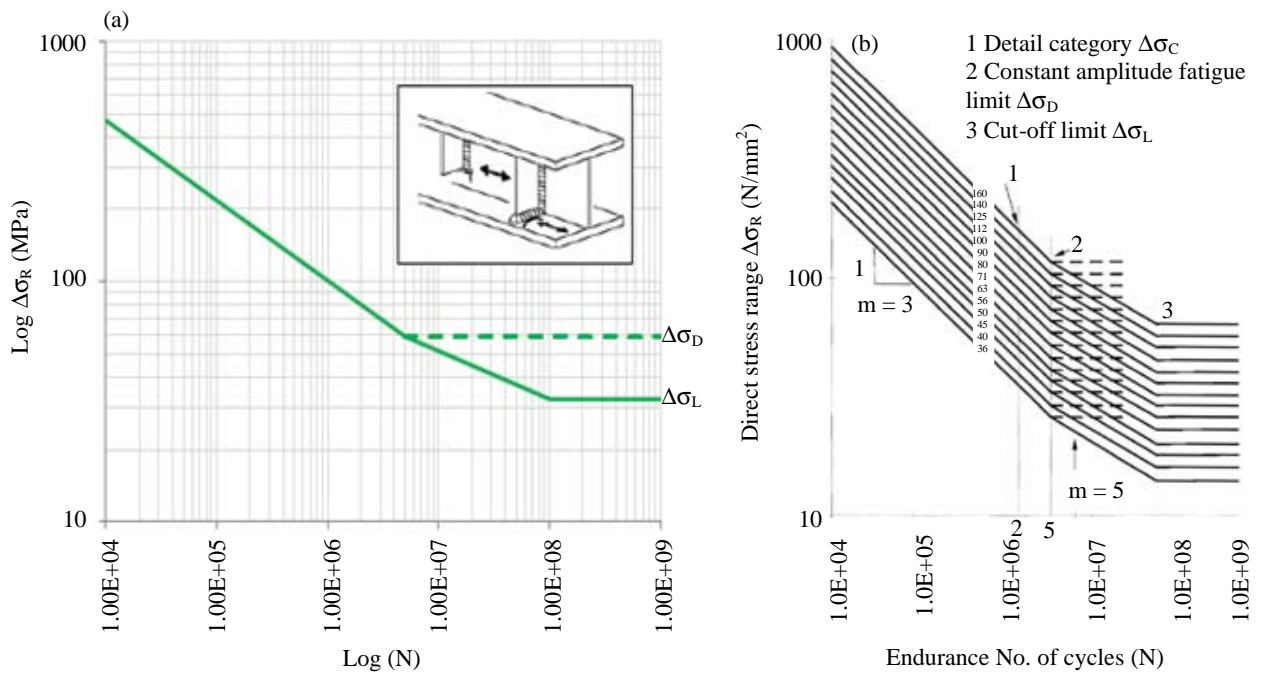

Fig. 20: a and b) Fatigue strength curves

between the vertical stiffeners welded to the web of the left main girder of the bridge which is classified as class " 80 " as shown in Fig. 20. In the current study, the fatigue damage assessment for the Al SABTIA Bridge was limited only to this class (Kwad et al., 2017). The fatigue damage calculated as follow (Miner, 1945):

$$
\mathrm{D}=\frac{\mathrm{nl}}{\mathrm{N} 1}+\frac{\mathrm{nl}}{\mathrm{N} 1}+\frac{\mathrm{nl}}{\mathrm{N} 1}+, \ldots,=\sum_{\mathrm{i}=1}^{\mathrm{k}} \frac{\mathrm{ni}}{\mathrm{Ni}} \leq 1.0
$$

$$
\begin{aligned}
& N_{i}=N_{c}\left[\frac{\Delta \sigma_{c} / \gamma_{m f}}{\gamma_{\mathrm{mf}} \Delta \sigma_{\mathrm{c}}}\right]^{\mathrm{m}} \text { can also be written as } \Delta \sigma_{\mathrm{c}} \text { is the } \\
& \mathrm{N}_{\mathrm{i}}=2 \times 10^{6}\left[\frac{\Delta \sigma_{\mathrm{c}} / \gamma_{\mathrm{mf}}}{\gamma_{\mathrm{Ff}} \Delta \sigma_{\mathrm{c}}}\right]^{3}
\end{aligned}
$$



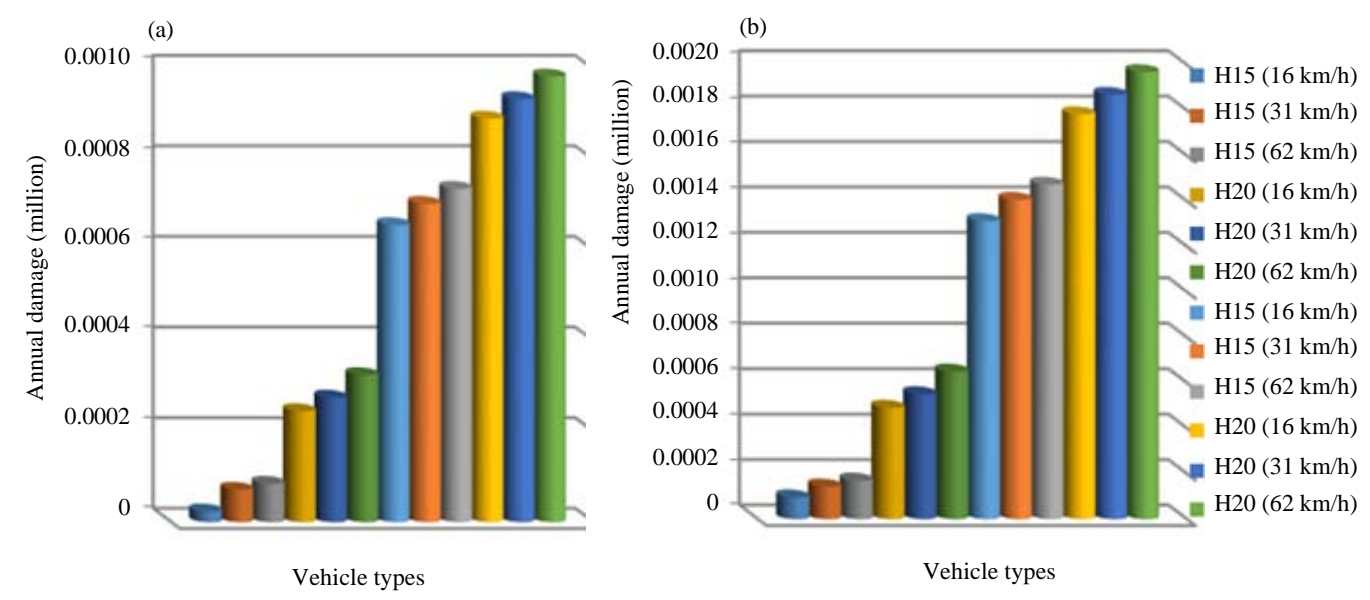

Fig. 21: Fatigue damage at the critical position using vehicles per year: a) 0.5 million and b) 1.0 million

Table 5: Fatigue damage in the critical position
\begin{tabular}{llcc}
\hline Items & Location & Fatigue damage using 0.5 million vehicles per y ear & Fatigue damage using 1.0 million vehicles peryear \\
\hline 1 & At top face of concrete deck slab & 0.000041 & 0.000078 \\
2 & At interface between concrete and steel girder & 0.000120 & 0.000230 \\
3 & At bottom of steel flange girder & 0.000459 & 0.000918 \\
\hline
\end{tabular}

The dynamic analyses using the fatigue vehicles with different speeds such as $(16,31$ and $62 \mathrm{~km} / \mathrm{h})$ that applied and simulated on the composite bridge using finite elements approach by ANSYS and then transfers the stress range analysis results to the MATLAB Software by rain flow (ASTM E1049-85, 2005). Figure 20 presents the damage for each type of vehicle considering 1 and 0.5 million. vehicles per year per lane that matched the function and requirement of ALSABTEA bridge design.

Figure 21 shows the total damage for each fatigue vehicle types that were considered in this study and the total annual damage for all vehicles was 0.0009185 by assuming that $10^{6}$ vehicles/year/lane. However, this damage was for 2 million. vehicles ( 1 million/lane/year). From Table 4 number of vehicles expected per year was used 0.5 million/lane. So that, the total annual damage become 0.000459296. Finally, the total damage for the critical for a 10 years period is 0.00459296 .

The worst case as analysis result lists in Table 5 the maximum Damage index (D) occur in the bottom face of composite steel girder that represent accumulative fatigue at this point, so that, recommendation to strength in the steel girder at the location for maximum concentration by stiffener at bottom flange with thickness and match the fatigue requirement.

\section{CONCLUSION}

Fatigue performance of composite bridge under the effects of moving loads based on AASHTO truck loading using finite element analysis by ANSYS and a computer program code written by MAT LAB Software. According to the analysis results the fallowing points are concluded: deflection at the bottom face of the steel girder increase as applied loadings due to load concentration of heaver load and become maximum at the mid span of composite bridge due to symmetry and cumulative deflection of nodes.

Increase in truck speed led to increase in deflection due to increase in kinetic energy. Bending stress at location of bottom steel girder, interface and top face of concrete deck slob increase as the applied external load increase and become maximum. Shear stress at interface increase in magnitude as the applied load increase due to increase in shear flow the developed from external load. The analysis result indicated that the Damage index D for load cases not reach to unity but the maximum value is $<0.2 \%$ in case of HS20 loading.

The fatigue damage $\mathrm{D}$ at present time for Al-SEBTEA Bridge, if checking by adopt any methodology should be not create than 0.0045 for 10 years. The worst case as analysis result indicated that the maximum Damage index (D) occur in the bottom face of composite steel girder that represent accumulative fatigue at this point.

\section{REFERENCES}

AASHTO., 1996. Standard Specifications for Highway Bridges. 16th Edn., American Association of State Highway and Transportation Officials, Washington, DC., USA. 
ACI., 2014. Building code requirements for structural concrete (ACI 318-14): Commentary on building code requirements for structural concrete (ACI 318R-14): An ACI Report. American Concrete Institute. Michigan, USA.

ASTM E1049-85, 2005. Standard practices for cycle counting in fatigue analysis. ASTM International, West Conshohocken, Pennsylvania, USA. https://www.astm.org/DATABASE.CART/HISTOR ICAL/E1049-85R05.htm

Abbas, A.L., 2011. Non-linear analysis of continuous composite concrete-steel beams under cyclic loadings. Diyala J. Eng. Sci., 4: 125-143.

Anonymous, 2018. Users manual revision. Ansys Software Private Limited, Chennai, India.

Kwad, J., G. Alencar, J. Correia, A. Jesus, R. Calcada and P. Kripakaran, 2017. Fatigue assessment of an existing steel bridge by finite element modelling and field measurements. J. Phys. Conf. Ser., 843: 1-13.

Law, S.S. and X.Q. Zhu, 2004. Dynamic behavior of damaged concrete bridge structures under moving vehicular loads. Eng. Struct., 26: 1279-1293.

Leitao, F.N., J.G.S. Da Silva, P.D.S. Vellasco, S.A.L. De Andrade and L.R.O. De Lima, 2011. Composite (steel-concrete) highway bridge fatigue assessment. J. Constr. Steel Res., 67: 14-24.
Lin, W., T. Yoda and N. Taniguchi, 2013. Fatigue tests on straight steel-concrete composite beams subjected to hogging moment. J. Constr. Steel Res., 80: 42-56.

Miner, M.A., 1945. Cumulative fatigue damage. J. Appl. Mech., 12: A159-A164.

Panchal, D.R., 2014. New techniques of analysis and design of composite steel-concrete structures. Intl. J. Eng. Res. Technol., 3: 639-643.

Sadiq, S.E. and A.R. Hassan, 2016. Transient stress analysis of simply support beam excited under moving load. Al Qadisiya J. Eng. Sci., 9: 331-348.

Salem, A., 2013. Dynamic analysis and fatigue assessment of bridge decks subjected to traffic and corrosion effects. MSc Thesis, Department of Civil and Environmental Engineering, Colorado State University, Fort Collins, Colorado.

Wang, W., L. Deng and X. Shao, 2016. Number of stress cycles for fatigue design of simply-supported steel I-girder bridges considering the dynamic effect of vehicle loading. Eng. Struct., 110: 70-78.

Zhang, W., 2012. Fatigue performance of existing bridges under dynamic loads from winds and vehicles. Ph.D Thesis, Department of Civil and Environmental Engineering, Tongji University, Shanghai, China. 